\title{
KESC's 2002 multi-year tariff determination: lessons for Pakistan and South Asia*
}

Ian Alexander, Aftab Raza, ${ }^{1}$ and Joseph Daniel Wright ${ }^{2}$

Senior Economist, South Asia Energy and Infrastructure Unit, The World Bank, Washington, DC, USA

International Journal of Regulation and Governance 3(2): 161-194

\begin{abstract}
In preparation for privatization of the KESC (Karachi Electricity Supply Company), a state-owned vertically integrated electricity utility in Pakistan, the company requested that the regulatory body NEPRA (National Electric Power Regulatory Authority) grant a MYT (multi-year tariff). The new regulatory framework was proposed to assure the prospective investor would be allowed a reasonable period to recover the losses of the initial years of privatization before the base tariff is adjusted through a review. Thus permitting a much smaller initial price increase than would have been necessary if an MYT framework were not established.

The MYT - established by NEPRA in September 2002 - is essentially a consumer price index-X price-cap on the controllable costs of KESC while uncontrollable costs are considered on a passthrough basis. The assurance to earn reasonable returns and incentives to make investment are based on the investor's ability to meet efficiency targets, especially those relating to losses, set by NEPRA. The adoption of MYT for KESC is a radical shift from a rate of return regime to a performance-based regulation in the power

\footnotetext{
* The views expressed in this paper reflect those of the authors and should not be attributed to their employers. Comments were received from participants at a SAFIR workshop on multi-year tariffs in South Asia, held in August 2003 (Raza 2003) as well as from $\mathrm{C}$ hris Shugart, $\mathrm{Clive} \mathrm{H}$ arris, and Bernard Tenenbaum. $\mathrm{H}$ el pful comments were also received from an anonymous referee. Any remaining errors are the responsibility of the authors.

${ }^{1}$ Aftab Raza is the Senior Economist at the Regulation and Supervision Bureau for the Water and Electricity Sector of the Emirate of A bu D habi, U nited Arab Emirates. ${ }^{2}$ Joseph Wright is a young professional in the World Bank's South Asia Energy and Infrastructure U nit.
} 
sector of Pakistan. Similar MYT schemes are expected to be introduced for other distribution companies in the country.

This paper briefly reviews the most salient features of the MYT that has been established. As the first clear MYT in the energy sector in South Asia, there are lessons in this determination that other regulators and regulated companies should consider. Issues for consideration have also been noted. 


\section{Background on Karachi Electricity Supply Company}

B efore considering the specifics of the M YT (multi-year tariff), it is useful to consider the power sector in Pakistan and the characteristics of the company that had requested the determination.

$T$ he generation, $T \& D$ (transmission and distribution), and retail supply of electricity in Pakistan is presently undertaken by two vertically integrated public sector utilities - KESC (K arachi Electricity Supply Company) and the WAPDA (Water and Power Development Authority) - with significant contribution to generation from various private thermal IPPs (independent power producers). ${ }^{3}$ WAPDA supplies power to all of Pakistan, except the metropolitan city of $\mathrm{K}$ arachi and some of its surrounding areas, which are supplied by KESC. Electricity in Pakistan is produced in various thermal (oil and gas $4590 \mathrm{M} \mathrm{W}$; coal $150 \mathrm{MW}$ ), hydroelectric ( $5009 \mathrm{M} \mathrm{W}$ ), and nuclear power plants ( $325 \mathrm{M} \mathrm{W}$ ); however the generation by the KESC system is predominantly from thermal oil and gas power plants (Government of Pakistan 2003). T he government has embarked upon a plan to restructure and deregulate the power sector by corporatizing and privatizing the state-owned electricity utilities. The power wing of WAPDA is in the final stages of being unbundled into a number of generation, $T \& D$ companies with a number of these companies earmarked for privatization in the near future. In contrast to WAPDA, KESC is planned to be divested as a vertically integrated utility. NEPRA ( $N$ ational Power Regulating Authority) was established in 1995 but was formally notified as an independent regulatory body for the electricity sector in Pakistan through an act passed in 1997.4

KESC is a vertically integrated electricity supply company undertaking all elements of the supply chain-generation, transmission, distribution, and retail supply. ${ }^{5}$ It provides services to a customer base of 1.7 million, predominantly urban, customers in an area of about $6000 / \mathrm{km}^{2}$ (square kilometres) in the Sindh and Baluchistan regions of Pakistan. The total population in its licensed area is estimated at well over 10 million. Initially established as a private company in 1913, the GoP (Government of

\footnotetext{
${ }^{3}$ As on June 2002 , a little over one-third of the generating capacity was provided by IPPs-6332 M W out of a system total of 17953 M W. (Government of Pakistan 2003). ${ }^{4}$ C opies of this act are available from the NEPRA web site (www.nepra.org.pk).

${ }^{5} \mathrm{KESC}$ is in the process of acquiring separate licenses as per the requirements of the 1997 Act. Distribution and supply are treated as a single licensed activity.
} 
Pakistan) took majority control of KESC in 1952 while leaving the company listed on Pakistan's three stock marketsIslamabad, Karachi, and Lahore. Presently, the government ownership in KESC is about $98 \%$ (Government of Pakistan 2003a). In 1999, there were about 12500 employees of KESC.

While KESC owns and operates four power stations (total installed capacity of $1756 \mathrm{M} \mathrm{W}$ ), it also purchases power from various other sources. ${ }^{6} \mathrm{~T}$ hese include

- WAPDA which is the main electricity utility for the rest of Pakistan;

- state-owned companies such as Pakistan Steel and KAN U PP (K arachi N uclear Power Plant); and

- directly from two IPPS.

The load characteristics for KESC are provided in Table 1. KESC has been facing financial losses since 1996 due to high technical losses, pilferage, and high cost of power purchases. System losses have increased from $17 \%$ in 1985/86 to $40 \%$ in 2001/02 (Figure 1). Experiments with public sector management through non-traditional methods, including the induction of army personnel in uniform as top managers since 1999 did not show any signs of significant improvement. It is recognized that even substantial tariff increases may not increase revenues of KESC due to the possibility of customer shift to own-generation and increase in pilferage. Privatization is therefore considered by many as the better or, rather, the only way out.

Annexe 1 provides the information on the financial position of KESC while the issue of losses is discussed in more detail later in this paper.

Table 1 Load characteristics for Karachi Electricity Supply Company in 2000/01

\begin{tabular}{lr}
\hline Element & MW \\
\hline Base demand (night-time) & 831 \\
Base demand (daytime) & 1752 \\
Peak demand & 1860 \\
\hline
\end{tabular}

Source Available at www.kesc.com.pk

${ }^{6}$ T wo of the power stations are purely gas fired while the other two are oil- or gas-fired stations. 


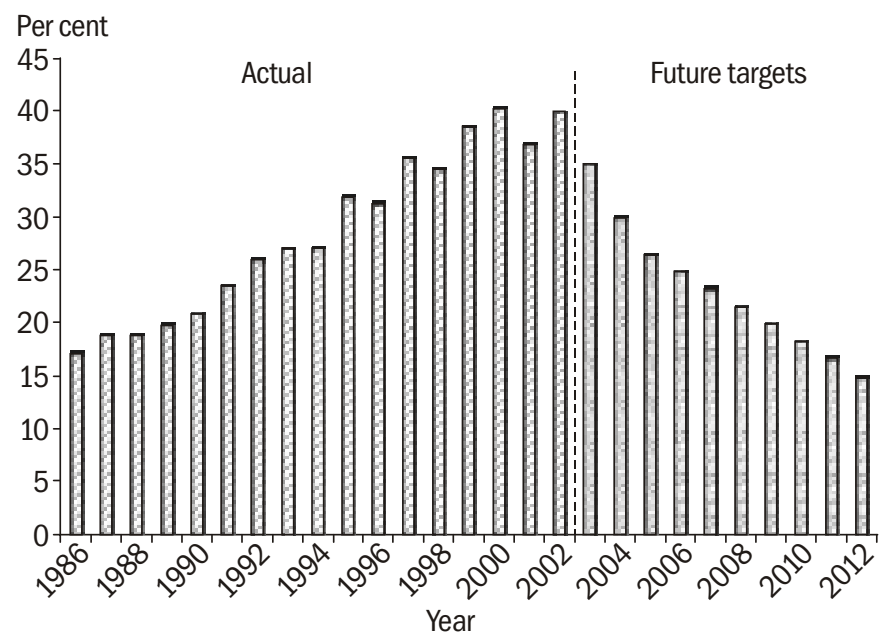

Figure 1 Karachi Electricity Supply Company's transmission and distribution losses Source Tariff Determination in Case No. NEPRA/TRF-14/KESC 2002

Part of the preparation for privatization of KESC has also been a financial restructuring aimed at clearing the accumulated losses of the business and making the forward-looking situation more acceptable. Consequently, during 2002 the G oP 7

- converted 83.176 billion rupees of debt into equity; and

- wrote-off 57.202 billion rupees of capital to eliminate accumulated losses.

KESC is planned to be divested as a vertically integrated utility through the sale of $51 \%-74 \%$ of total equity with management control to a strategic buyer. Various target dates for privatization have been set and lapsed without success at least since 1997. M ost recently, preliminary information to investors was issued in $M$ arch 2002. Although several potential bidders expressed an interest, the process again lapsed. A further push for privatization was commenced in 2003 with a plan for completing the sale process early in 2004.

Expected privatization has raised the question about the certainty regarding tariff that the privatized KESC can charge its customers. The regulation of KESC to date has been on an ad hoc basis and driven by the compulsion to compensate KESC for its losses and inefficiencies.

\footnotetext{
${ }^{7}$ T hese actions were supported by a loan and technical assistance from the Asian D evelopment Bank.
} 


\section{Regulation of KESC to date}

NEPRA was established in January 1995 under an ordinance and was formally notified in January 1998 after the passing of the act in 1997. It finalized its Tariff Standards and Procedure Rules in December 1998. NEPRA's Tariff Rules allow formulabased tariff designed to be in place for more than a year. H owever, the regulation of KESC and WAPDA has been on an ad hoc basis, at least until the determination on M YT.

KESC filed its first petition in July 1999 for tariff decrease by $1.61 \%$, which was approved by NEPRA in August 1999. KESC's second petition was submitted in August 2000 by the $M$ inistry of Water and Power on behalf of KESC. This was for an automatic fuel adjustment formula to compensate KESC for changes in fuel price for KESC's own-generation or external sources of generation, in the form of adjustment to the average rate of sale. The adoption of automatic fuel adjustment formula was a significant step towards the formula-based M YT.

KESC's tariff was not precisely based on ROR (rate of return) regulation. In recent years, the actual cash outflows mostly exceeded the estimates because of higher actual losses as compared to targets and increased debt service liabilities. Consequently, NEPRA accepted that the inability of KESC's management to achieve the stipulated target of losses created the compulsion to resort to tariff increases or increased financial support from the government (in the form of subsidy or equity).

\section{NEPRA's determination on MYT scheme}

In M ay 2002, KESC filed a petition before NEPRA seeking an increase of $16 \%$ in the average customer tariff and approval of a formula-based M YT for the next 10 years. Prior to this submission, the G OP had requested NEPRA to consider the possibility of granting a M Y T in M arch 2001. ${ }^{8}$ T he tariff was proposed to be reviewed after a period of 10 years and thereafter every five years. On 10 September 2002, N EPRA finalized the determination on KESC'S submission and duly sent this to the Cabinet Secretary as per NEPRA's law (GoP has 15 days to assess the proposal and request any reviews). In its determination, NEPRA approved the MYT framework for KESC while making a

${ }^{8} \mathrm{~T}$ he economic advantage of incentive- or performance-based regulation as compared to a cost of service or ROR regulation have been acknowledged in many countries, including the UK, US, Australia, and Abu D habi (UAE). 
Table 2 Components of base tariff for Karachi Electricity Supply Company

\begin{tabular}{lllllr}
\hline & \multicolumn{2}{l}{ Average sale rate } & & \multicolumn{2}{l}{ O\&M component } \\
\cline { 2 - 3 } \cline { 5 - 6 } Tariff component & Rs/kWh & $\%$ of total rate & & Rs $/ \mathrm{kWh}$ & $\%$ of total rate \\
\hline Generation cost & 2.43 & 51 & & 0.10 & 2 \\
Power purchase cost & 1.48 & 31 & & $\mathrm{NA}$ & $\mathrm{NA}$ \\
Transmission cost & 0.30 & 6 & & 0.04 & 1 \\
Distribution cost & 0.53 & 11 & & 0.32 & 7 \\
Total & 4.74 & 100 & & 0.46 & 10 \\
\hline
\end{tabular}

Rs - Pakistan rupees; kWh - kilowatt hours; NA - not applicable; O\&M - operation and maintenance

Source Tariff Determination in Case No. NEPRA/TRF-14/KESC 2002

number of changes to the proposal (Figure 2). T he framework is described below.

1 The base tariff for M YT shall be the prevailing average customer tariff with an initial increase of $6.5 \%$. Table 2 shows various components of the base tariff.

2 For the period up to the end of 7 years after privatization, the average sale rate shall be subject to the following adjustments.

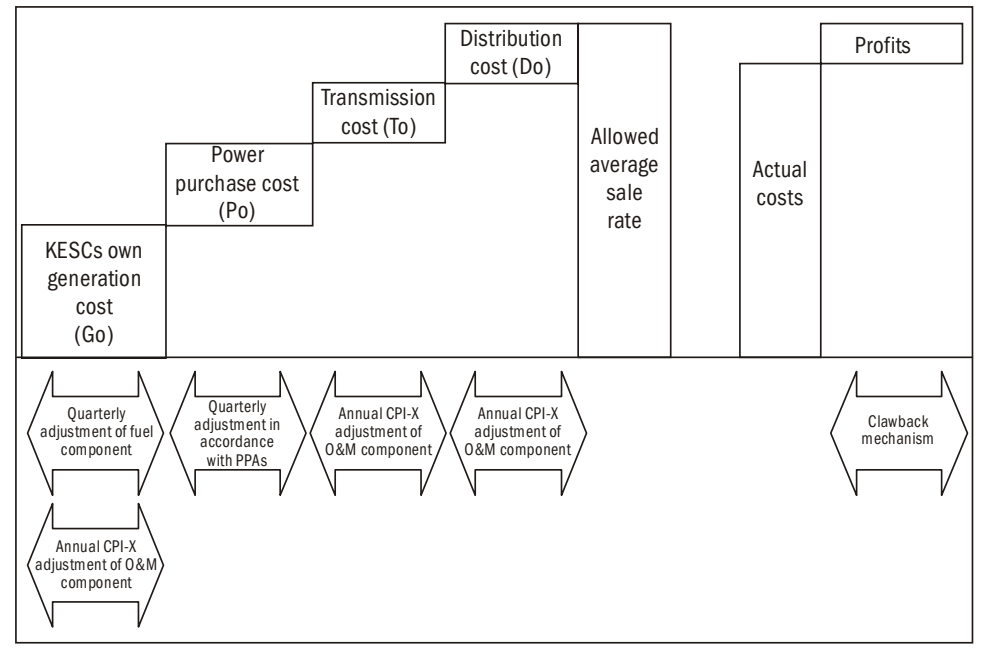

$\mathrm{CPI}$ - consumer price index; 0\&M - operation and maintenance; PPA - power purchase aggrement

Figure 2 Multi-year tariff framework for regulation of Karachi Electricity Supply Company Source Tariff Determination in Case No. NEPRA/TRF-14/KESC 2002 
Table 3 Percentage efficiency factor $(X)$ for Karachi Electricity Supply Company

\begin{tabular}{lll}
\hline 0\&M component & First 3 years & Next 4 years \\
\hline Generation cost & 0 & 2 \\
Transmission cost & 0 & 2 \\
Distribution cost & 0 & 3 \\
\hline
\end{tabular}

O\&M - operation and maintenance

Source Tariff Determination in Case No. NEPRA/TRF-14/KESC 2002

- Quarterly adjustment for variation in fuel component of KESC's own Go (generation costs) due to fuel price variations during the previous quarter.

- Quarterly adjustment for variation during the previous quarter in power Po (purchase cost) in accordance with the power purchase agreements with external sources (for inflation, exchange rate variation, fuel price variation, and so on).

- Yearly adjustment to $O \& M$ components of Go,To, and Do by applying the Pakistan CPI (consumer price index)based inflation rate for the previous year less an efficiency factor $X$. Table 3 shows the factor $X$ for various $O \& M$ (operation and maintenance) costs.

3 To avoid significant tariff fluctuations from one quarter to another, a number of measures shall apply to quarterly tariff adjustments. In particular, the quarterly tariff adjustment for fuel cost variation shall be limited up to a maximum of $2.5 \%$ and power purchase cost variation up to $1.5 \%$ (a quarterly limit of $4 \%$ in total). These limits shall apply separately such that the respective remaining burden or relief is transferred separately to the next quarter.

4 A CBM (clawback mechanism) shall apply whereby the profits accruing to KESC beyond a predetermined real ROR on asset (before tax and interest) in a certain year is shared with consumers through tariff reduction in the next year. T he consumers' share increases as the profits increase beyond certain levels of ROR. Profits shall be shared between consumers and KESC if the equivalent ROR is

- in excess of $12 \%$ in the ratio of $25: 75$;

- in excess of $15 \%$ in the ratio of 50:50; and

- in excess of $18 \%$ in the ratio of $75: 25$. 
Lack of data on which the scheme can be based is a problem that has been raised during discussions of MYT schemes elsewhere in South Asia. While NEPRA was forced to grapple with data issues, these were not seen as insurmountable. F urther, the inclusion of a sharing system, discussed later in this paper, helps provide protection against abnormal profits arising from data mistakes.

\section{Assessment of a new regulatory framework}

According to NEPRA, the purpose of an MYT for KESC is to

- assure the incoming investor that the profits through reduction in technical losses, pilferage, and other efficiency measures over a certain period will be sufficient to compensate for the financial losses expected in the initial years;

- better serve the general public interest through economic efficiency, least cost service, and improved service quality; and

- bring more predictability in consumer tariffs by restricting the tariff adjustments to known indicators such as fuel price and inflation indices.

M YT has certain obvious strong advantages, like certainty for investors and customers, compared to the traditional $\mathrm{ROR}$ regulation. Since the approved MYT is based on the CPI-X pricecap, it also provides strong incentives for KESC to reduce losses and costs to earn and retain profits-although these are blunted to some extent by the CBM . While the principles are simple, the devil is in the details of how the framework is designed. The following sections briefly review the most salient features of the M YT that has been proposed, such as

- certainty and predictability of tariff for investors and customers,

- form of control and its associated incentives and risks,

- the determination of the allowed ROR,

- targets for loss reductions,

- $0 \& M$ efficiency targets,

- process for pass-through of certain uncontrollable costs, and

- the time scale allowed for review of petition.

As the first clear MYT in the energy sector in South Asia, there are clearly lessons in this determination that other regulators and regulated companies should consider. 


\section{Certainty and predictability of tariff}

It is often argued that privatization and regulatory strategies must work together. Regulatory uncertainty is usually considered as the major obstacle to successful privatization. Potential investors have the perception that the tariff-setting methodologies used by the regulatory agencies in Pakistan and other countries of the region lack certainty, as they fail to clearly define the price-path for the future that can assure the investor of recovery and earning a return on investment. However, the concern that has been mostly raised by possible investors is the uncertainty about the tariffs. The owner of a distribution company recently privatized (which then went into problems) in Orissa (India) considered MYT as imperative for resolving deep-rooted problems with the government and regulator. The World Bank has identified risky and weak regulatory frameworks for infrastructure (including electricity) in Pakistan as one of the four key reasons for the government's failure to improve the investment climate in the country (D awn 2002).

The regulatory uncertainty is the inability of investors to predict with confidence what tariffs they will be allowed to charge after privatization. Investors' concern is not the levels of tariffs but their certainty. This is because the levels of tariffs, if certain, can be incorporated by the investors into the bid at the time of privatization. The value that an investor bids for the asset is simply the present value of the estimated net cash flows from the asset. Tariff being the source of revenue is the main input to this asset valuation exercise.

The investor may not be concerned much with losses that the company is presently suffering, as it indicates the potential for improvement and hence profits that the investor can make. However, this is to the extent that such losses are not beyond a company's or an investor's control.

In fact, regulatory certainty was the main reason for the government's proposal as well as the regulator's decision to adopt $M Y T$ for KESC. NEPRA forecasted that with MYT and KESC meeting its targets for system losses, KESC or the investor should be able to reduce its cumulative losses to zero during the next three years (2003-05) and to earn a reasonable accumulative overall return over 7 years (2003-09). This is shown in Figure 3 along with historical trends. 


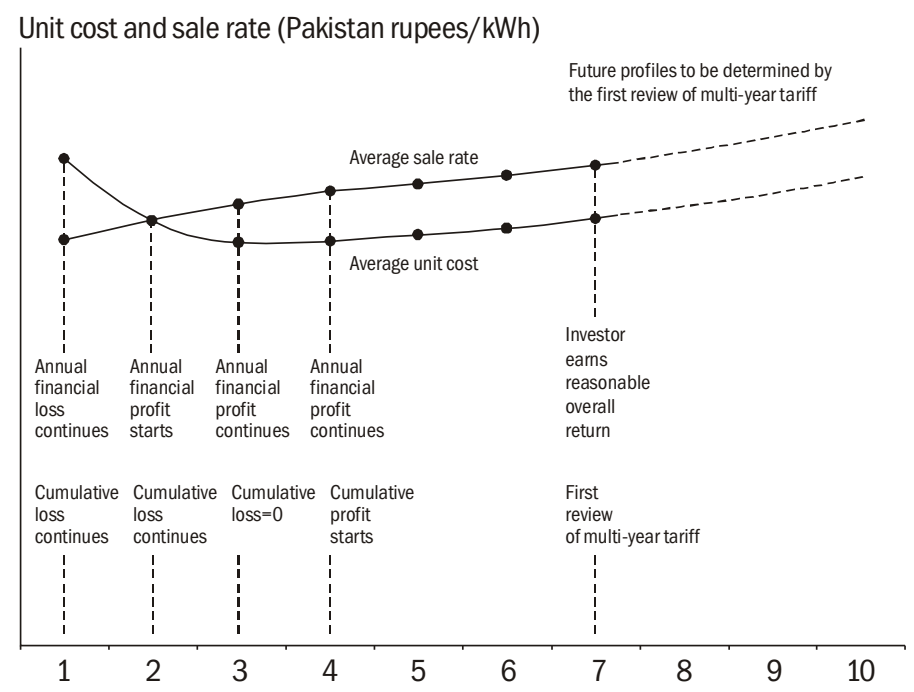

Figure 3 Expectations under the KESC multi-year tariff

Source Tariff Determination in Case No. NEPRA/TRF-14/KESC 2002

The MYT will not only provide the certainty for investors in KESC but also to its customers. Customers also appreciate certainty about the price-path since it allows them to plan future expenditure. $\mathrm{H}$ aving prices that vary significantly from year to year, let alone quarter to quarter, may make some budgeting decisions difficult for both industry and households. Providing certainty to customers through M Y T price-path helps overcome this difficulty.

An uncertainty which remains with the regulation of KESC is the absence of any clear-cut commitment from NEPRA about the continuity of M YT framework in the event of a future price review. That is whether the incentive-based M $M T$ will continue after 7 years from privatization, with new base tariff and $X$ factors at the next review. In any case, the investor is likely to seek the required commitment from the government at the time of privatization, possibly backed by sovereign guarantees or some form of regulatory guarantee from a multilateral organization (G upta, Lamech, M azhar et al. 2002).

\section{Form of control}

While determining an M YT, the first question which the regulator needs to assess is what form should the proposed M Y T take? $\mathrm{T}$ here are four key characteristics that need to be considered. 
Table 4 Scope of regulatory control

\begin{tabular}{|c|c|}
\hline Element & Scope of control \\
\hline Generation & $0 \& \mathrm{M}$ is subject to $\mathrm{CPI} \mathrm{X}$ incentives, other costs passed-through \\
\hline Purchased power & Entirely a cost pass-through \\
\hline Transmission & $\begin{array}{l}\text { All costs subject to price-cap regulation, } 0 \& \mathrm{M} \text { is subject to } \mathrm{CPI}-\mathrm{X} \\
\text { incentives }\end{array}$ \\
\hline Distribution & $\begin{array}{l}\text { All costs subject to price-cap regulation, } 0 \& \mathrm{M} \text { is subject to } \mathrm{CPI}-\mathrm{X} \\
\text { incentives }\end{array}$ \\
\hline
\end{tabular}

$0 \& M$ - operation and maintenance; $C P I-X$ - cost price index-X

Source Tariff Determination in Case No. NEPRA/TRF-14/KESC 2002

1 Scope of the control

2 Type of the main control: price-cap, revenue-cap or hybrid?

3 Risks associated with the allowed ROR

4 Period of control.

\section{Scope of control}

As discussed in the background, KESC undertakes all aspects of the electricity supply chain, as well as purchasing power from private and separately state-owned generators. As the main reforms in Pakistan have been aimed at unbundling the electricity supply company, KESC will be subjected to separate licences and each of the licensed businesses will be separately regulated.

So, there are four separate forms of control, as detailed in Table 4. T he relative importance of each aspect is discussed later in this paper.

\section{Type of cap}

Once the scope of controls for various elements are set, the regulator then needs to answer that, for the three elements that are subject to incentive regulation, what form does this control take? Three options are available: price-caps, revenue-caps, and hybrids (combinations of the two) ${ }^{9}$ In each case, NEPRA decided that a price-cap was an appropriate way of maximizing incentives for the operator to

- increase sales;

${ }^{9} \mathrm{~T}$ he differences between these approaches and the implications for incentives and gaming are described in Alexander and Shugart (1999). 
- improve the quality of service and over a period of time slow and even reverse the move to own-generation;

- reduce technical and non-technical losses; and

- reduce controllable costs.

Although the issue of controllable costs is also addressed through the direct determination of revenue, creating positive incentives was felt to be appropriate. NEPRA also stated that the creation of maximum incentives for KESC was appropriate owing to the starting point of having costs greater than revenues and NEPRA's desire to ensure a fair initial price increase. ${ }^{10} \mathrm{~F} \mathrm{ur}$ ther, as discussed in the following section, mechanisms were also approved to share any significant upward benefits from the incentives with the customers through a CBM .

\section{Rate of return risks}

O ne by-product of price-caps is the possibility of earning significant levels of profit if the number of units sold increases rapidly (possibly due to unforeseen growth, faster than expected reductions in losses or gaming by the company at the time of setting the control). Some of these factors are under the control of the company, whereas others are not. Accordingly, to share some of the potential benefits from faster sales growth (and other actions that increase profitability) a sliding scale system is also proposed.

What is suggested and approved is an asymmetric sliding scale-the upside is shared but not the downside. It is also the case that different levels of sharing are suggested, so that incentives for the company are tapered. The proposed system is set out in Table 5.

Table 5 Real return on assets

\begin{tabular}{lllll}
\hline Percentage of share & $<12 \%$ & $12 \%-15 \%$ & $15 \%-18 \%$ & $>18 \%$ \\
\hline Consumers & 0 & 25 & 50 & 75 \\
Company & 100 & 75 & 50 & 25 \\
\hline
\end{tabular}

Source Tariff Determination in Case No. NEPRA/TRF-14/KESC 2002

${ }^{10} \mathrm{KESC}$ had initially requested a price increase in excess of 40\% (F ebruary 2002 petition) but had subsequently requested a lower increase of $16 \%$ ( $M$ ay 2002 petition) and was allowed $6.5 \%$ by NEPRA (September 2002 determination). 


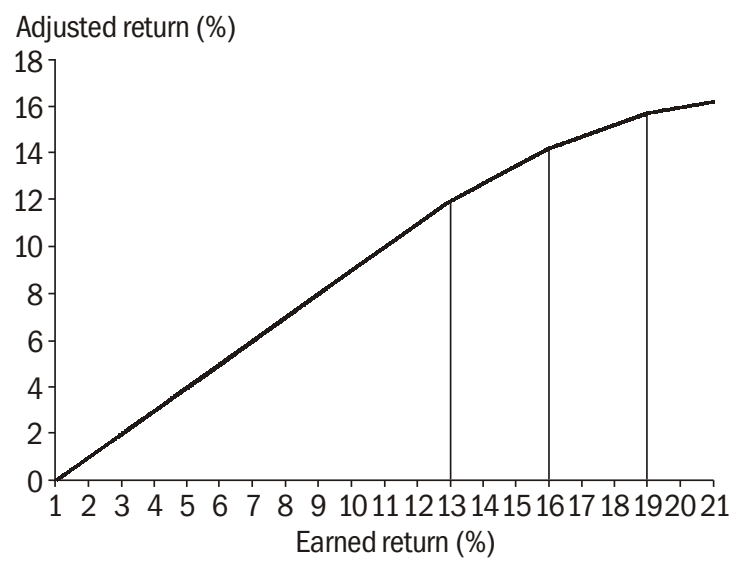

Figure 4 The impact of the sliding scale clawback mechanism on out-turn of profits Source Tariff Determination in Case No. NEPRA/TRF-14/KESC 2002

The base level of real return on assets (12\%) was determined through a consideration of some market data. The real risk-free ROR in Pakistan is about $8 \%$ at the moment with an appropriate risk premium for the sector of $4 \%$.

$\mathrm{N} O$ attempt to measure the required ROR through models like the CAPM was presented in the tariff determination. However, some evidence on the basis for the determination of the $12 \%$ estimate was presented at a SAFIR workshop on Regional Pricing Strategy at a ater point, which is evaluated in the following section.

What does the sliding scale system imply for profitability ( $F$ igure 4)? T here are also implications for the overall return earned by the company owing to the interaction of the adopted sliding scale system and the revenue-smoothing system. Of course, the M YT for KESC does not guarantee an ROR, however it assures KESC an ROR over a long term if it manages costs efficiently as envisaged. The expected ROR s of $12 \%, 15 \%$, and $18 \%$ are used to assess only the reasonability of the review period and limits of profit sharing in the CBM.

While there seems to be no strong possibility that KESC will earn any profit in the early years of MYT and any significant profits even in the later years, the CBM should be regarded as a good attempt to further reduce such possibility in view of the quality of cost data provided by KESC and to avoid any political or public relations damage to the regulatory framework in case the investor makes windfall profits. $\mathrm{H}$ owever, the design of $\mathrm{CBM}$ has two inherent flaws. 
1 The mechanism is subject to manipulation. KESC can increase its regulatory asset base (and thus reduce actual ROR) by adjusting the timing of investment that is by bringing forward investment when the threshold ROR is expected to be exceeded so as to reduce the ROR by increasing the regulatory asset base.

2 Profit sharing is subject to discrete levels of RORs. That is, the same profit-sharing percentages apply to a wide range. For example, the sharing ratio 25:75 applies to returns in the entire range of $12 \%-15 \%$. I deally, the scheme should have been continuous or should have many small ranges, so that the customers' share of profits would have increased more rapidly with increase in return than what is allowed under the present design.

While the latter point will help overcome some of the perverse incentives for manipulation of the CBM system, it however also increases the complexity of the system. As such, any regulator needs to trade-off the complexity, with associated costs, and the incentives created for gaming the system.

Period of control

KESC in its submission to NEPRA requested a 10-year price control period. NEPRA, in its assessment of the proposed length of the control, took the following issues into account.

- M ost international evidence on the length of price controls is between 3 and 5 years; and

- KESC, unless significant initial price increases are allowed, would continue to make losses for several years.

D ue to the latter point, NEPRA chose a pragmatic approach: trying to weigh future profits against the initial losses, while being aware of GoP's plans for privatization. Given the $12 \%$ allowed real ROR, it was found that a zero or positive NPV (net present value) was possible after 7 years. So, a 7 -year price control period has been approved by NEPRA. NEPRA's determination, however, does not contain the actual analysis or calculations leading to the 7-year conclusion. $T$ his may raise the issue of transparency in the regulatory process making it difficult for interested parties to replicate such calculations and convince themselves of the justification of a 7-year duration. 
Clearly, choosing a price control period that is long by international standards has the following implications.

- The potential for significant cost shocks to occur

- The potential for unanticipated demand growth to lead to significant abnormal profits; and

- U nanticipated shocks affecting investment requirements that could have a significant impact on the company by requiring it to undertake investment not anticipated when the price control was set and consequently not rewarded during the life of the price control.

The regulatory system should be designed in a manner to help control some of the implications. For example,

- the profit-sharing system should protect against abnormal profits becoming an issue; and

- the cost pass-through elements for uncontrollable costs should protect against unanticipated shocks.

However, it is not clear that the investment issue will be sufficiently captured through the proposed system. This could prove to be an important point. For example, KESC's generation plants and networks require massive investments. H owever, the base tariff does not incorporate any investment plan nor does the M YT framework provide any explicit assurance for recovery of any investment (for example, there is no discussion of how an asset base will be calculated and updated). In other countries where CPI-X (or even ROR) regulation is in vogue, the utility is provided with an allowance for its prudent investment and any investment plan underlying such allowance is carefully monitored.

NEPRA has argued that the approved MYT provides an incentive for investment in capacity expansion by allowing KESC to increase its revenue through increase in consumer base and increase in sales or consumer without any restriction. Investment in system refurbishment will reduce losses and consequently generation costs and hence will be rewarded as increased profits. If the reduction in losses exceeds the efficiency targets, the company will earn more profits. With a larger asset base (which would avoid triggering of CBM ), KESC will be able to retain most of the resulting profits.

H owever, it is not obvious that the benefits of investment (increased sales and profits through capacity expansion and reduction 
in losses and generation costs) will be enough to recover the actual investment with reasonable returns. As far as the profit sharing through CBM is concerned, as noted above, it may provide incentives to the company to manipulate its ROR to avoid or reduce any profit sharing with the customer, rather than to provide direct incentives for investment. It could be argued that the investor will take into account investment requirements while submitting its bid at the time of privatization rather than to make investment in response to any indirect incentive of M YT.

A further issue that should be considered when thinking about the period of the control is the linkage with privatization that N EPRA has created. While NEPRA had approved the M YT for a period of 7 years commencing from the date when KESC is privatized, it had to come into effect prior to the privatization that was expected to be completed in the calendar year 2002. Although such an application may be desirable for certainty, better efficiency incentives, and a successful transition phase, it must be recognized that the continuing public ownership may ultimately place a limit on the efficiency improvements that can be achieved.

A key issue relevant to the duration is raised, 'What will happen if privatization is delayed considerably?' If KESC is not privatized, say, for 2 to 3 years, the MYT period will run for about 9 to 10 years which may have some undesirable outcomes. In particular, a state-owned KESC will be subject to the MYT principally designed for a privatized KESC and to performance targets that have not been achieved so far. KESC may therefore ask for revision of approved MYT or for additional tariff increases if the privatization is significantly delayed.

Efforts are under way again to hasten the progress of privatization. As noted earlier, the existing privatization plan is based on a sale in early 2004. As such, NEPRA has continued with the application of the MYT even though it does have the option of switching to a more prescriptive approach, as set out in the original determination. While this is laudable as per the points set out above, there does have to be some concern about applying an incentive-based approach to a company whose corporate governance is such that if does not necessarily respond to standard corporate goals. This has been an issue in India where several regulators, most recently the $U$ ttar Pradesh Electricity Regulatory Commission, have commented on the problems of creating effective incentives for state-owned companies (UPERC 2003). 
With hindsight, NEPRA could have set a target date for privatization of KESC, say 2 years and then have had two separate M YT s: one M YT for up to 2 years when KESC is not privatized and another MYT for 5 years after privatization. The former M YT could be revised if KESC is not privatized in 2 years based on the circumstances and latest information. This approach would have capped the total duration to 7 years and addressed other concerns. Presently, the total duration of the approved M YT could be interpreted as open ended, although that does not seem to be the approach being adopted by NEPRA.

\section{Determination of the allowed rate of return}

As noted earlier, the $12 \%$ of allowed ROR (Alexander [forthcoming]) was recently explained in a presentation by one of the members of NEPRA. It was built up accordingly

\section{Cost of equity}

Element

(1) Market return

(2) Risk-free rate

(3) Market risk premium

(4) Equity beta (based on US data )

(5) Country risk

(a) Cost of equity

Cost of debt

(b) Average cost of debt

Capital structure

(c) Debt

(d) Equity

Cost of capital

Weighted average cost of capital

\author{
Estimate \\ $11 \%$ \\ $8 \%$ \\ $3 \%$ \\ 0.66 \\ $2 \%$ \\ $(2)+[(4) \times(3)]+(5)=12 \%$
}

$55 \%$

$45 \%$

$[(a) \times(d)]+[(b) \times(c)]=12.2 \%$

Undertaking a full assessment of the applicability of this number is beyond the scope of this paper. H owever, some initial observations can be made.

\section{$M$ ethodology}

Within the standard WACC (weighted average cost of capital) approach adopted by NEPRA, three methodological issues can be raised. 
1 M ixing of forward-looking and backward-looking approaches;

2 clarity about what is being measured; and

3 the need to make adjustments to the beta value.

The approach adopted by NEPRA for the cost of equity is the standard CAPM. T his is a forward-looking approach to estimate the cost of equity and is employed by many regulators in developed and developing countries. H owever, the approach adopted for the cost of debt is a backward-looking assessment of the rates at which the company has been able to borrow money: this is a more traditional approach to the cost of debt, especially when the cost pass-through of interest is allowed. However, the backward-looking cost of debt approach is inconsistent with the cost of equity approach when combined like this in the WACC. Forward-looking costs of debt are likely to be significantly lower than those at which the company has borrowed in the past since there has been a significant shift downwards in the risk-free rate.

While there may be some circumstances in which it is appropriate to view interest payments as a cost pass-through item, it would be more appropriate to keep this as a separate item and to focus on a cost of equity approach. Further work on the cost of debt would seem appropriate.

Linked to the above issue is the one of exactly what is being estimated. There are many different basis on which WACC can be calculated. These depend on the view as to whether it is the position of the company being considered or that of the investor and whether returns are measured pre- or post-tax (Alexander [forthcoming]). The determination of exactly what is being measured is important since it affects how other elements of the cost-flow are being incorporated into the revenue requirement. For example, if post-tax figures are being employed then tax payments need to be included as a separate cash-flow item-that is not necessary if a pre-tax figure is being utilized. Clarity about this will allow the consistency of the revenue requirement calculation to be determined.

Equity betas are a reflection of two factors:

- the underlying business risk, referred to as the asset beta; and - the capital structure of the company.

In relation to the equity beta - the measure of the relative risk of the business - there are two adjustments that should have been considered 
- the form of regime employed; and

- the capital and tax structures of the company relative to the comparator.

Business risk is, itself, a function of several factors. O ne of these is the type of regulatory regime-different types of regime leave the operator more or less exposed to general economic conditions. As such, when using comparative data to establish an estimate of the business risk, it is important to ensure that either companies facing similar regime types are used, or that an allowance is made for the regime type. In the case of KESC, the US data was employed to establish the business risk.

No single type of regime is used in the US, rather different states use different approaches ranging from the traditional ROR regulation to earnings-sharing (profit-sharing), and pricecaps (Williamson 2001). As such, clarity about the exact comparator used and whether the regime was comparable to that being proposed for $\mathrm{K}$ arachi is necessary to establish whether the right comparator was being used.

Secondly, as noted above, the capital structure of a company also has an impact on the equity beta value. So, an asset beta is the better starting point since this can then be adjusted to the capital structure proposed for the company being regulated rather than just using the capital structure of the comparator. Again, clarity about the comparators utilized would help determine if the approach was appropriate. ${ }^{11}$

\section{Estimates}

While much of the methodology employed is standard across regulators, the estimates employed need further analysis. For example, the market risk premium is an estimate of the additional average annual return required to hold a basket of all assets rather than just the risk-free asset. Traditional values for this in developed countries have focused between $6 \%$ and $9 \%$ while more recent evidence has suggested values between $3 \%$ and $4 \%$, which might be more appropriate (Jenkinson 1998). So, the proposal by NEPRA to employ a value of $3 \%$ would suggest that either a relatively aggressive estimate has been taken, or that there is a strong belief that the international capital markets are

${ }^{11}$ T here are also arguments about needing to adjust for taxation when de-leveraging an equity beta value. This is discussed in Alexander (forthcoming). 
efficient. It may be that a higher figure could be appropriate for Pakistan for which the state of the Pakistan market would need to be evaluated.

F urther, the use of a country's risk premium is a good way to correct the fact that U S data is primarily being employed to calculate the risk premium. However, a $2 \%$ premium would seem to be low for Pakistan. Evidence on comparable borrowing rates for countries with different ratings is provided in a range of journals including the Financial Times. While data are not specifically provided for Pakistan, it is possible to consider premia paid by comparable countries. T his evidence would bolster the justification for the numbers used. For example, in D ecember 2003 the Philippines Government was paying a premium of $1.18 \%$ more than the US Government to borrow money while the Brazilian G overnment was paying $4.67 \%$ (F inancial T imes 2003). This information can be collected from various sources and can be considered as an input to determining an appropriate country-risk premium.

\section{Comparable estimates for other infrastructure providers}

A final source of information, which can help establish the appropriateness of a regulatory estimate, are the rates allowed for other companies. One example here is the fact that OGRA, the gas regulator, allows gas $T \& D$ companies to earn $R O R$ between $17 \%$ and $17.5 \%$. T he basis for these estimates is less clear that is the basis on which the estimates of $17 \%$ and $17.5 \%$ were established, but the fact that these figures are significantly higher than those allowed by NEPRA should signal that further analysis is required.

Overall, NEPRA has taken a major step forward by setting out calculations that it employed when deriving the $12 \%$ allowed ROR figure. While there are some issues about the methodology and the estimates involved, these issues can be refined.

\section{Losses}

While an incentive-based system has been established for $0 \& M$ costs of various elements of the company, however the possibility of additional profits arising from outperforming these incentives is limited.

Like the rest of South Asia, the largest 'controllable' cost that a company faces is related to losses-losses that are outside the 
scope of the $O \& M$ incentive scheme but captured or incentivized within the price-caps for different elements. If KESC can reduce its losses, it will earn additional profits to the extent allowed by the CBM .

Figure 1 illustrates the evidence on losses for KESC since the mid-1980s. Although some periods of slight improvement have been seen, most recently in 2001, the overall trend has been for the situation to become worse.

NEPRA in the determination make two specific comments about losses

- losses for the financial years 2003 and 2004 should be $35 \%$ and $30 \%$, respectively; and

- that within a 10-year period the operator should be able to reduce losses to $15 \%$.

This was supplemented by some further information in the financial projections suggesting that

- auxiliary consumption (the own use of power by the generating plant) would drop from $6.1 \%$ to $5.8 \%$ over 3 years; and

- the forecast of T\&D losses for 2005 was $26.5 \%$, suggesting a further 3.5\% point improvement from 2004.

Since no specific details are given about how this long-term decline should be phased, the diagram assumes a constant rate of improvement to reach the $15 \%$ from the 2005 figure.

H ow possible is a $10 \%$ improvement in 2 years? It is clear that concerted efforts, as seen occasionally, since the mid-1990s can lead to improvements above $2 \%-3 \%$. But these improvements have never been sustainable.

It is also not clear as to where the majority of the losses lietechnical or commercial? O wing to the poor financial position of KESC over the past few years, there has been a significant reduction in the investment programme. Consequently, it is not possible to determine whether the rapid deterioration in the losses is due to technical issues, linked to the reduction in investment, or the more general commercial problems raised by law and order issues.

What is clear is that there is an issue of commercial losses in Pakistan, and if previous experience is anything to go by then a significant element of the KESC losses will be commercial. As such, it ought to be possible for reductions to be made in a timely manner, although it will also be important to ensure that 
these savings are then cemented rather than being lost in a matter of years. ${ }^{12}$

\section{Efficiency}

When thinking about the main aspects of efficiency, apart from the question of loss addressed above, there are three things worth considering:

1 How important are the $O \& M$ costs?

2 What efficiency factors are proposed and how were they determined?

3 What is the planned evolution of real $O \& M$ costs?

\section{Importance of $O \& M$ costs}

The cost structure of the existing electricity system and the relative importance of $O \& M$ costs are given in Table 2 . It shows that although $O \& M$ costs account for only about $10 \%$ of the total cost of delivered electricity, they account for over $60 \%$ of the distribution costs.

\section{Efficiency factors}

KESC accepted the need for efficiency factors and made the following proposal. They also suggested that a $0 \mathrm{X}$ factor be adopted for the first 3 years of the price control (Table 6).

NEPRA decided against linking the $X$ factor to the inflation rate, believing that the factors determining $X$ were independent of the inflation rate. Rather, they considered

- the potential impact of too aggressive $X$ factors on quality of service;

Table 6 KESC (Karachi Electricity Supply Company)'s proposed X factors

\begin{tabular}{ll}
\hline Rate of inflation (\%) & $X$ factor $(\%)$ \\
\hline$<0$ & 1.0 \\
0 to 5 & 2.0 \\
5 to 8 & 2.5 \\
$>8$ & 3.0 \\
\hline
\end{tabular}

Source KESC petition, May 2003

${ }^{12} \mathrm{KESC}$ is also likely to come under further pressure from WAPDA to ensure that the losses are constrained. KESC has been a major source of receivables for WAPDA and given the increasingly tight budget constraints imposed by GoP there will be pressure to ensure that this is not the case in the future! 
- the need to ensure that the $X$ factor captured the industry efficiency rather than company specific;

- the fact that $T \& D$ losses are the most significant efficiency/ cost factor; and

- incentives for investment to promote capacity expansion should be ensured.

Given these factors, $X$ factors in Table 3 have been proposed for the $O \& M$ costs of the different elements of the industry. For 4 to 7 years they provide an overall target of about $2.7 \%$ of controllable costs. Figure 5 illustrates the evolution of the controllable costs over the lifetime of the control.

Figure 5 shows that NEPRA has set efficiency factors $(X)$ at zero for the first 3 years and then $2 \%-3 \%$ for subsequent years. While the zero efficiency factor for an early period of M YT is adopted in other countries, $2 \%-3 \%$ of $X$-factors for subsequent years are on the lower end of the $X$ factors adopted by other regulators-this also does not take into account the significant cut in base tariff made by regulators at every 4 to 5 years. For example, the UK electricity regulator's second price controls for distribution companies stipulated one-time price cuts in the range of $11 \%-17 \%$ for an $X$ factor of $2 \%$. The next price controls resulted in more significant price cuts (18\%-35\%) with an $X$ factor of $3 \%$. In Victoria (Australia), the regulator set $X$ factors in the second price controls for distribution costs in the

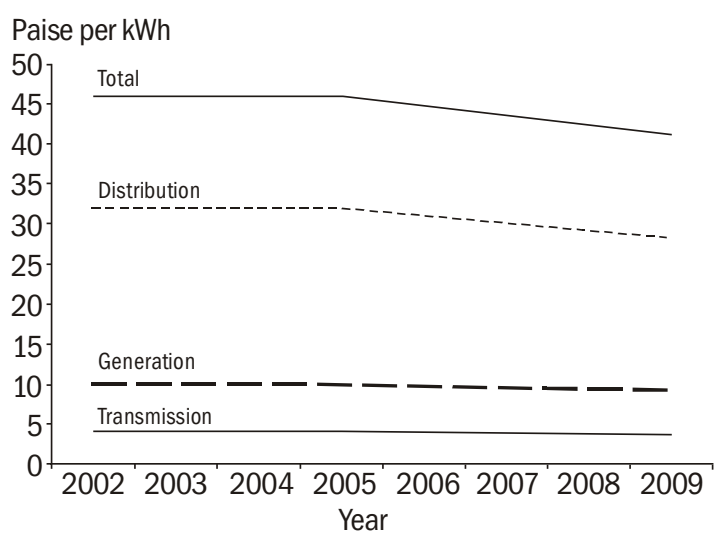

Figure 5 The evolution of operation and maintenance costs over the life of the proposed price control

Source Tariff Determination in Case No. NEPRA/TRF-14/KESC 2002 
Table 7 Annual real unit operating cost reductions in UK utilities since privatization

\begin{tabular}{lrrrrrrrr}
\hline & 1992 & 1993 & 1994 & 1995 & 1996 & 1997 & 1998 & CAGR \\
\hline Electricity transmission & 15.6 & -6.1 & -15.0 & -14.4 & -7.0 & -6.4 & -11.1 & -6.5 \\
Electricity distribution & -3.3 & -1.5 & 1.8 & -5.8 & -12.5 & -14.4 & -8.9 & -6.8 \\
\hline
\end{tabular}

CAGR - Compound Annual Growth Rate

Source Adapted from ORR (1999)

range of $12 \%$ and $22 \%$ in 2001 and thereafter $1 \%$ each year from 2002 to 2005.

F urther, the UK experience shows that the actual efficiency improvements made by companies have been well above those assumed by the regulators in setting price controls. Table 7 shows the annual real unit operating cost reductions in the UK electricity utilities since privatization. T he average annual reduction is about $6.5 \%-6.8 \%$ (Estache, Guasch, and Trujillo 2003). ${ }^{13}$ These improvements are calculated after taking into account of the effect on costs of changes in output levels and the level of service quality, and so can be taken to represent 'underlying' efficiency improvements. The efficiency improvements actually made by the utilities are more relevant than the efficiency improvements assumed, as the former indicate the extent of efficiency improvements that can actually be realized.

T hough the above range indicates the potential of cost reduction by privatization and management and technological developments, the extent of cost reduction that can actually be achieved depends - among other things - on the environment a utility operates. H owever, it may be argued that KESC's present situation indicates a greater extent of efficiency improvements that can be achieved compared to the U K utilities. Although it is worth noting that the $X$ factors for KESC are in addition to the system loss reduction targets set by the regulator.

In general, the establishment of a non-zero $X$ factor for KESC should be considered as a good step in the right direction. CPI$X$ price-caps can successfully work for state-owned utilities; however it is recognized that the continuing public ownership of an entity may ultimately place a limit on the efficiency improvements that can be achieved.

${ }^{13}$ Evidence from L atin America is also available. 


\section{Evolution}

Given these $X$ factors and the relative costs of each segment of the industry, it is possible to determine the evolution of $O \& M$ costs over the life of the price control (Figure 5). If the total costs of electricity supply in $\mathrm{K}$ arachi are considered, the $\mathrm{X}$ factors amount to an effective $0.15 \%$ of an annual efficiency target (or an annual efficiency target of $1.5 \%$ of $O \& M$ costs) over the life of the price control.

\section{Cost pass-through}

As mentioned when discussing the form of price control, the vast bulk of costs are treated on a cost pass-through basis. This section considers four elements of cost pass-through:

1 the fuel price adjustment formula;

2 the PPA (power purchase agreement) adjustment formula;

3 the process by which the adjustments are made; and

4 the cap to the maximum allowed change in any one quarter.

\section{Fuel price adjustment}

For own-generation, the largest uncontrollable cost is fuel. A fuel cost pass-through system had been initiated in 2000/01 for the Pakistan electricity sector but this has not been successful (primarily due to process issues described below). In the KESC determination, a new version of the adjustment mechanism is proposed which also separates power purchase adjustments from pure fuel cost changes.

For the fuel cost pass-through, consider the following example.

Consider five quarters

$\mathrm{Q}_{0,1}$ (actual), $\mathrm{Q}_{0,2}, \mathrm{Q}_{0,3}, \mathrm{Q}_{0,4}, \mathrm{Q}_{1,1}$

A change in fuel costs during $Q_{0,1}$

Then estimate the impact over the actual quarter $\left(Q_{0,1}\right)$ and the next three quarters $\left(Q_{0,2}\right.$ to $\left.Q_{0,4}\right)$

Assessment of costs is based on the actual price for current quarter and this new price as the forecast for the next three quarters (done in paise per $\mathrm{kWh}$ ). U sing the actual generation and forecast generation, the revenue impact can be determined. 
Revenue is then recovered as a paise per $\mathrm{kWh}$ adjustment over the next four quarters $\left(Q_{0,2}\right.$ to $\left.Q_{1,1}\right)$, thus smoothing the impact by - allowing for seasonal variations in production/use of fuel; and - not having to recover the current quarters higher costs immediately but spreading it over the following four quarters.

So, this approach dampens volatility but could become extremely messy if frequent fuel cost changes occur.

\section{Power purchase}

Power purchase costs from IPPs are basically treated the same way as fuel costs (a consideration of the change for the current quarter being assessed over the next three quarters and then recovered over the next year) but it is all costs rather than just fuel costs.

\section{Process}

As noted above, one of the issues with the fuel cost pass-through over the past year or two has been the process by which it is applied. T he G oP had requested NEPRA to find an automatic system for allowing quarterly changes in fuel costs. NEPRA contends that the 1997 act does not allow for automatic changes in tariffs, any change must be notified to the G oP and placed in the official Gazette.

To facilitate the timely implementation of the pass-through mechanism, NEPRA provided a prescribed form for any request. T his simplifies the process and ensures that the evaluation does not become as time consuming as a price determination.

In an attempt to clarify how NEPRA believes this system should work, the following are given below.

- The company is allowed to request an automatic change each quarter, with the dates for the quarters clearly set.

- Within 4 days of receipt of request, KESC will be allowed to implement the change (subject to having to refund any difference if so determined).

- As quickly as possible, and no later than one month after receiving the request, NEPRA will finalize the determination and submit to the GoP.

In view of the apprehension that KESC may not be prompt to request for an adjustment in case of an expected decrease in tariff in a relevant period (which would be unfair to customers), 
then NEPRA shall take a suo moto action based on quarterly or yearly adjustments due to fuel price, power purchase, and profit for clawback.

\section{Cap to quarterly changes}

Under the existing fuel cost pass-through system, a maximum quarterly change of $3 \%$ is permissible. KESC proposed that this be changed to $5 \%$.

NEPRA reviewed the issues and determined that the following maximum $4 \%$ cap (with carry-over of any under recovery but no interest cost allowance) be established using

- a cap of $2.5 \%$ of the final retail tariff for the fuel cost adjustment; and

- a cap of $1.5 \%$ of the final retail tariff for the power purchase adjustment.

It is also proposed that any failure to meet targets of losses should not benefit from the cost pass-through protection. Thus, investigation to consider losses and additional sales will be required to ensure that the protection is not provided.

H owever, the investor needs to assess the risks associated with the limits that the regulator put on the quarterly adjustments to the tariff. T he furnace oil and gas prices have increased on average by about $15 \%$ and $8 \%$ per annum, respectively, over the past 5-6 years. O ver a longer term (1993-2002), such average annual increases are about $18 \%$ and $12 \%$, respectively. Assuming that the fuel price variation would be in the range of $8 \%-18 \%$ per annum over the control period (which translates into quarterly variation of $2 \%-4 \%$ ), the quarterly adjustment to the fuel component of $\mathrm{Go}$ which makes about $50 \%$ of average sales rate will result in about $1 \%-2 \%$ increase in average sales rate and, hence being below the limit of $2.5 \%$, be allowed.

However, if the fuel price increase is significantly high (like the $70 \%$ per annum increase in 1996/97), the investor will not be able to pass on full fuel cost increases for sometime. Any cost of borrowing or working capital to support increases needs to be assessed carefully as the MYT framework for KESC does not allow any interest to be applied on late recovery of fuel costs (and power purchase costs) from the customers.

Equally important is the issue of customer affordability. The success of M YT depends on whether the customer will be able to afford frequent and significant tariff rises, and whether the 
political government will let such a framework function as envisaged. Some of the automatic fuel cost adjustments over the past year have not been as timely as expected, partly owing to government concerns about the implications of such increases.

In the rare case, a maximum of $4 \%$ quarterly tariff adjustment for fuel and power purchase costs (which translates into $17 \%$ of annual tariff increase) and $0.3 \%-1.3 \%$ of annual tariff adjustment for CPI-X indexation (based on the actual inflation of $2.7 \%-13 \%$ per annum during the past ten years) may be required. T his translates into an overall annual increase in tariff by $17.3 \%-18.3 \%$, the affordability of such increases has to be questioned whether borne directly by consumers or indirectly through taxation if the G overnment chooses to subsidize the tariff.

\section{Privatization}

Finally, NEPRA made some comments about the application of the MYT scheme being linked to the privatization efforts. In principle, the MYT is only enacted once privatization has occurred since the whole rationale is related to providing certainty and incentives for a private operator. If this fails to materialize, some additional directions are provided by NEPRA relating to issues such as the size of receivables, rehabilitation of KESC's own-generation facilities, and so on. KESC would then be able to file further tariff petitions as it had done previously. H owever, as noted above, the system is effectively being utilized and a price increase as per the M Y T was processed during the summer of 2003.

While it is not explicitly stated, NEPRA is basically following the view that it is not possible to create incentives for stateowned enterprises. In the vast majority of cases this would appear to be an appropriate assumption (Irwin and Yamamoto 2003).

\section{Implementation processes and time scales}

NEPRA's tariff rules provide formula-based tariff designed to be in place for more than one year. T hese rules set out the standards and criteria to be followed while NEPRA examines and decides on a tariff petition. T he rules also clearly lay down the procedure for dealing with a petition from the date of filing of the petition till the final determination of NEPRA and decisions on any review motions or reconsideration request by the government. NEPRA has to decide on tariff petition within 6 months 
of the filing of a petition. In practice, more time is required for a comprehensive review of tariff if it is to be in place for a long time ( 5 to 7 years). Regulators in other countries where M YT is in operation conduct thorough consultations over an 18 to 24 month period and publish a number of consultation papers before arriving at any decision. NEPRA needs to assess this aspect of its procedure, and ensure more transparency and objective consultation with interested parties.

\section{Conclusion}

NEPRA's determination of a MYT for KESC reflects the first serious attempt in South Asia to create a comprehensive M YT system for an electricity company (Agarwal, Alexander, and Tenenbaum 2003). ${ }^{\mathbf{1 4}}$ There are many positive aspects to this which other regulators in the region and internationally can learn from. These include

- the reasoning for the length of the control period and certainty, incentives and risks for prospective investor;

- the building of elements of a regime to control for shocks, abnormal profit concerns and so on; and

- the process solutions for automated quarterly adjustments.

There are, however, some areas that require further investigation. These include, but are not limited to

- the treatment of, and incentives for, investment: no explicit rules for the regulatory asset base, inclusion of investment, treatment at the end of the period are provided;

- whether the $12 \%$ real ROR is sufficient;

- lack of details in the determination on various aspects for example, ROR, appropriateness of duration; and

- inadequate time ( 6 months) allowed by NEPRA tariff rules for determination on such a long-term M YT - international regulatory practice on $\mathrm{CPI}-\mathrm{X}$ price review suggests 1-2 years.

While the last point need not be an issue if the sale price is allowed to be below the nominal value of the equity, it would be an issue for future reviews.

${ }^{14} \mathrm{~T}$ he Delhi privatization which occurred in the summer of 2002 involves some elements of an M YT system, but is not a comprehensive determination. 


\section{Annexe $1 \mathrm{KESC}^{\prime}$ s financial position ${ }^{15}$ \\ Profit and loss statement}

Table shows the financial results of the Corporation for the last three financial years ending 30 June 2001 and for the 9 months ending M arch 2001 and 2002.

\begin{tabular}{|c|c|c|c|c|c|}
\hline \multirow[b]{3}{*}{ Description } & \multicolumn{3}{|c|}{ Year ended 30 June } & \multicolumn{2}{|c|}{ Nine months ended 31 March } \\
\hline & 1999 & 2000 & 2001 & 2001 & 2002 \\
\hline & Audited & Audited & Audited & Unaudited & Unaudited \\
\hline \multicolumn{6}{|l|}{ Revenue (rupees in million) } \\
\hline Energy sales & 23285 & 25035 & 28118 & 20278 & 21875 \\
\hline Other income & 496 & 1007 & 722 & 404 & 554 \\
\hline Total revenue & 23781 & 26042 & 28840 & 20682 & 22429 \\
\hline \multicolumn{6}{|c|}{ Expenditure (rupees in million) } \\
\hline Cost of fuel consumed & 9312 & 13916 & 17717 & 12390 & 13338 \\
\hline Electricity purchased & 11401 & 12202 & 13780 & 10095 & 8821 \\
\hline \multicolumn{6}{|l|}{ Depreciation and } \\
\hline other expenses & 7160 & 7141 & 7704 & 5778 & 5635 \\
\hline Loss before interest & $\left(\begin{array}{l}4 \\
092\end{array}\right)$ & (7 217) & $(10361)$ & $(7581)$ & $(5365)$ \\
\hline \multirow[t]{2}{*}{ Interest } & 3273 & 5569 & 5840 & 4380 & 6598 \\
\hline & 3273 & 5569 & 5840 & 4380 & 6598 \\
\hline Loss before tax & (7 365) & (12 787) & (16 201) & (11 961) & (11 963) \\
\hline Tax & 119 & 130 & 152 & - & - \\
\hline Loss after tax & (7 483) & (12 917) & (16 353) & (11 961) & (11 963) \\
\hline \multicolumn{6}{|l|}{ Transmission and } \\
\hline distribution losses (\%) & 38.6 & 40.2 & 36.8 & 35.0 & 39.8 \\
\hline Average tariff (Rs) & 3.799 & 3.894 & 4.061 & 3.898 & 4.410 \\
\hline
\end{tabular}

\section{Key points}

- The loss before interest grew rapidly during the three-year period to 30 June 2001, primarily as a result of fuel price increase not passed on to customers in full.

- Over the two years and nine months to $31 \mathrm{M}$ arch 2002, the C orporation's revenues have not even covered the cost of fuel and purchased power.

${ }^{15}$ T his information is taken from Section 4 of the $M$ ay 2002 tariff petition filed by KESC. 
- The poor financial performance of the Corporation reflects the continuing high level of energy losses suffered by the company.

- In the nine months to $31 \mathrm{M}$ arch 2002, the loss before interest showed an improvement relative to the prior year, mainly on account of

- lower power purchases as a result of increased availability of KESC generation,

- lower average fuel prices, and

- tariff increases allowed by NEPRA.

- The growth in loss before and after tax in the three-year period was even more dramatic, as a result of the growing interest burden from financing the continuing losses.

- In the financial year 2002/03, the improvement in losses before interest was more than offset by the continued increase in interest costs.

\section{Balance sheet}

The balance sheets at 30 June 1999, 2000, and 2001 and at 31 M arch 2002 are summarized below.

\begin{tabular}{|c|c|c|c|c|}
\hline \multirow[b]{2}{*}{$\begin{array}{l}\text { Description } \\
\text { (rupees in million) }\end{array}$} & \multicolumn{3}{|l|}{ June } & \multirow{2}{*}{$\begin{array}{l}\text { March } \\
2002 \\
\text { Unaudited }\end{array}$} \\
\hline & $\begin{array}{l}1999 \\
\text { Audited }\end{array}$ & $\begin{array}{l}2000 \\
\text { Audited }\end{array}$ & $\begin{array}{l}2001 \\
\text { Audited }\end{array}$ & \\
\hline Share capital and reserves & 10714 & 10714 & 10711 & 28546 \\
\hline \multirow[t]{2}{*}{ Accumulated losses - Net } & (19 319) & (32 236) & $(48589)$ & $(60552)$ \\
\hline & $(8605)$ & (21 523) & (37 878) & (32 006) \\
\hline Long term borrowings (> 1 year) & 44457 & 43347 & 48207 & 34393 \\
\hline Other long term liabilities & 4657 & 5247 & 6103 & 6745 \\
\hline Long term borrowings ( $<1$ year) & 2764 & 3723 & 8096 & 7401 \\
\hline Short term borrowings & 7931 & 8345 & 15041 & 22107 \\
\hline \multirow[t]{2}{*}{ Other current liabilities } & 18406 & 27035 & 27668 & 26780 \\
\hline & 69610 & 66174 & 67237 & 65420 \\
\hline Tangible fixed assets & 49751 & 49232 & 47865 & 46575 \\
\hline Other long term assets & 392 & 296 & 263 & 189 \\
\hline \multirow[t]{2}{*}{ Current assets } & 19467 & 16646 & 19109 & 18656 \\
\hline & 69610 & 66174 & 67237 & 65420 \\
\hline
\end{tabular}




\section{Key points}

- D ramatic growth in borrowings to finance growing losses.

- KESC has had to rely on the GoP to keep the Company afloat. The vast majority of KESC's borrowings are provided by, or guaranteed by, the GoP.

- On 28 February 2002, borrowings and liabilities were reduced by 17.8 billion rupees by way of a debt : equity swap.

- Tangible fixed assets have declined over the period, most particularly during the year ending 30 June 2001, reflecting the very low level of capital investment during recent years. Because of funding constraints, the capital expenditure programme has been severely curtailed.

\section{References}

Agarwal M, Alexander I, and Tenenbaum B. 2003

The Delhi electricity discom privatizations: some observations and recommendations for future privatizations in India and elsewhere Energy and Mining Board Discussion Paper Series No. 8 Washington, DC:T he World Bank

Alexander I. [forthcoming]

Cost of Capital: a practical guide for infrastructure regulators

Alexander I and Shugart C. 1999

Risk, volatility, and smoothing: regulatory options for controlling prices [mimeo] (available from the authors)

Dawn. 2002

WB identifies four key areas: investment climate

[A vailable at www.down.com/2002/10/16/ebe2.htm]

Estache A, Guasch J, and Trujillo L. 2003

Price-caps, efficiency payoffs and infrastructure contract renegotiation in Latin America

World Bank Policy Research Working Paper N o. 3129

Washington, DC: T he World Bank

F inancial Times. 2003 (12 D ecember)

UK: Financial times Publishing

Government of Pakistan. 2003

Power System Statistics, Pakistan

Government of Pakistan. 2003a

Privatisation Commission's web site

[Available at www.privatisation.gov.pk] 
G upta P, L amech R, M azhar F, and Weight J. 2002

Mitigating regulatory risk for distribution privatization: The World Bank partial risk guarantee

Energy and M ining B oard D iscussion Paper Series N 0. 5

Washington, DC: The World Bank

Irwin T and Yamamoto C. 2003

Improving the Governance of State-owned Power Utilities [mimeo]

Washington, DC: The World Bank

Jenkinson T. 1998

The equity risk premium: another look at history

The U tilities J ournal

Oxford: OXERA

ORR (Office of the Rail Regulator). 1999

The Periodic Review of Railtrack's Access Charges: Provisional Conclusions on Revenue Requirement

UK: ORR

Raza A. 2003

Multi-year tariff for power sector in Pakistan: step in the right direction

SAFIR (South A sia Forum for Infrastructure R egulation) N ewsletter 12: 2-7

U PERC (U ttar Pradesh Electricity Regulating Commission). 2003

Petition N 0.32 of 2003 - In the matter of: A ggregate R evenue R equirement and

Tariff in FY 04 [A vailable at www.uperc.org accessed on D ecember 2003]

Williamson B. 2001

UK 'incentive' regulation: international best practice?

In Regulatory Review 2000/2001 M illenium edition,

UK : C entre for Regulated Industries 